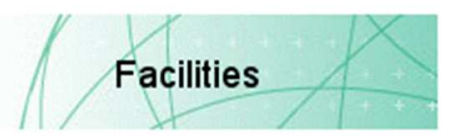

\title{
Leveraging BIM and Big Data to Deliver Well Maintained Highways
}

\begin{tabular}{|r|l|}
\hline Journal: & Facilities \\
\hline Manuscript ID & f-02-2016-0021.R2 \\
\hline Manuscript Type: & Original Article \\
\hline Keywords: & $\begin{array}{l}\text { Highways Management, Asset management, BIM, Big Data, Facilities } \\
\text { management, Data Management }\end{array}$ \\
\hline \multicolumn{2}{|l}{} \\
\hline
\end{tabular}




\section{Page 1 of 22}

\section{Facilities}

\section{INTRODUCTION}

The Highway infrastructure is one of the most valuable assets for any state or national Government (Taggart and Moss, 2015). Efficient operations of Highways lead to success of national and local economies as well as improve the quality of life of the general public dependant on it. In order to ensure aging road networks continues to move with its ever increasing number of users, requires maintenance and improvements to the road network at the highest standard. Increasing scrutiny over the cost of maintenance along with increasing pressure from Government and the public for transparency over road network spending, has made a strong case for more 
efficient management of the Highway road asset and traffic management data. Better management of information could allow for life cycle management of asset data and predictive analytics.

Data required for smooth operation of Highways could be split into various categories including a) Traffic volume, speed, journey time; b) Roadway data such as road surface condition, road marking, message signs, road surface markings, traffic junctions infrastructure, bridges on the network, c) road edge data such as shoulders, curbs, gutters, driveways, inlets, sidewalks, and d) roadside data such as ditches, storm water management infrastructure, vegetation, topographical information. Staff from different departments and organisations are involved in collection and maintenance of this data including Engineering, Traffic Management, maintenance and specialist service providers. Absence of an integrated approach to data management often leads to absence of an inventory of key assets and condition assessment, leading to maintenance operations which are often suboptimal. Even in situations where data is maintained, it is often in an unstructured format, which is difficult to analyse. Big data analytics provide approaches to identify patterns and trends in data, that can help identify opportunities for improvement.

An optimal data management strategy must begin from early road scheme design stage. In recent years, there has been tremendous growth in methods of handling engineering design information, evolving beyond CAD designs to 3D Parametric modelling/Building Information Modelling (BIM) enabled integrated digital design models. However, as highlighted by Steel et al (2012), 2D AutoCAD/Micro station based hardcopy sign off files are still most commonly used method of disseminating engineering drawings. Data included within these drawings include plan layouts (e.g. road layout, drainage, structure, signage, electrical, communications, etc.), 2D Views (e.g. profile, elevation, cross section) and non-graphical data (e.g. co-ordinate geometry, templates, networks). Data embedded in 2D drawings, such as survey data, sub-structure design data, location/survey data, could effectively be used to support asset management. However, effective utilisation of this data will require a consistent approach in design, construction and asset management. Reliance on traditional processes often based around exchange of 2D drawings lead to critical infrastructure data buried in piles of drawings, which can only be interpreted by human visual recognition, for scaling and approximate distance measurement, limiting information utility and processing capabilities. While prevalent sign-off contractual processes signify need for hardcopy signed off drawings, there is lack of appreciation of benefits interoperable digital data could bring in design, construction and lifecycle management of assets.

The UK Government Construction Strategy (2011) has outlined the requirement to have all projects using collaborative 3D BIM by 2016 (BIM Task Group, 2013a). Major infrastructure clients are required to meet such targets. In addition, Highways Administration authorities are under pressure to reduce congestion, improve network safety, and improve environmental outcomes. This paper reviews the value that can be generated through integrated life cycle data management of data as enabled by BIM (Fig 1). It is argued that data from the design and construction phases of projects can be used to inform asset registers from an earlier point in time. This information, including models, can be used to plan management and maintenance schedules. Moreover, it can also be integrated with data generated from numerous other sensors to develop a better picture of network operations and support key decision making. Big data analytics could help prioritise spending decisions, based on predictive life cycle modelling, based on whole life cycle modelling approaches, deterioration modelling and real time traffic information.

This paper focuses on proposing a platform that integrates various technologies and systems of Highways Authority and its supply chain, to allow for continuous flow of data throughout an asset'sassets life-cycle, leading to seamless, collaborative and effecting working. The integration takes into account developments in the area of BIM and big data; BIM provides a platform to better integrate information whereas big data can provide analytical platform to draw insights based on existing conditions of Highways assets through accurate asset management, and an ability to record and analyse ongoing construction work and its impact on the road network. Rest of the paper is organised as below. Section 2 presents research background where emerging standards for life cycle management of data are reviewed along with best practice case studies. The background assists in understanding the concept and structure of asset information models through the whole life cycle of asset management. Section 3 presents methodological approach, followed by presentation of a system architecture that integrates data from different disciplines. Section 5 explores opportunities for integration of Highways maintenance and operations data with big data. Conclusions are drawn in Section 6. 


\section{RESEARCH BACKGROUND}

While the value of capturing information from early project life cycle stages is starting to be realised, it is important for this information to be retained, enhanced and accessible at handover and in operations and maintenance stage of a facility. Handover stages are often associated with major information losses e.g. when project moves from construction to operations stage. Smooth flow of 'information' is of critical importance to make any collaborative system or modelling function effective. Capturing up-to-date and accurate information means the work that follows will be of value with waste reduced. For instance in road repair example, capturing information such as how road was it repaired, repair duration, used materials, cost, potential reasons for degradation (i.e. weather, increased traffic flow) etc. is a valuable knowledge base that can be taken into account on future projects. Accurate information can be fed into electronic collaborative workspaces, allowing Highways Administration and their supply chain to work together more efficiently. Specifications such as PAS 1192:3, which alongside PAS 1192:2, provide a structure for information management through the whole life cycle of asset management. PAS 1192:3 looks at the assets at operational level by creating an asset information model (BIM Task Group, 2013b). To use the model, the 'asset owning organisation' must identify their assets and numerous pieces of information about those assets to enable creation of the asset information model. A key element of this standard discusses information being available, transferable and having integrity. It includes how a Project Information Model (PIM) is transferred to become an Asset Management Model (AIM) (Mordue, 2013).

UK Government is also promoting use of Government Soft Landings Policy (GSL) (2012) to deliver smoother transition of information when project is handed over from design/construction to operations/maintenance stages. The client is involved from an early stage, engaging with design and construction teams to identify their requirements and expectations at the end of the process. This provides an opportunity to Highways Administration authorities to capture relevant information they require as they engage with their stakeholders, in order to meet varied expectations of Highways operations. Aforementioned initiatives provide necessary structures, which will inevitably help project teams deliver more efficient information as they are supported by a formal process and effective early engagement and support of the Client. Information in the final models will 
naturally mature through the design and construction processes, provided the teams maintain it throughout and transition project information for handover.

Operation and maintenance manuals submitted at the conclusion of projects can sometimes be late, incomplete or submitted as volumes of paper where information is difficult to find and update. Use of BIM in this area, either by following PAS 1192:3 asset management model or Government Soft Landings, allows information to be collated with a greater chance of reusability at handover to the user/operator at project completions. Table 1 provides a summary of BIM usage following the above mentioned standards in road development schemes and discuss how integrated workflows and processes may support life cycle management of assets. The two cases in the table highlight the benefits of a unified environment for data storage where various stakeholders have confidence in the accuracy and relevance in the information being exchanged among various parties.

Table 1: Case study review

\begin{tabular}{|c|c|c|}
\hline Case & Benefits Realised & Reference \\
\hline $\begin{array}{l}\text { The A556 project } \\
\text { The project objective is to transfer a } 4.5 \text { miles road into a modern } \\
\text { dual carriageway. Project used Level } 2 \mathrm{BIM} \text { throughout the project } \\
\text { from design, construction to operation stage. Fully coordinated } \\
\text { drawings were produced and cost information was integrated into } \\
\text { the 3D model to achieve a 4D model. Moreover, 3D Modeling was } \\
\text { used to develop a hazard risk register; capture accurate asset } \\
\text { information; and collate built information of pavements, footways, } \\
\text { lighting, ducting, drainage and structures, throughout the } \\
\text { construction phase }\end{array}$ & $\begin{array}{l}\text { - Improved monitoring and } \\
\text { scheduling } \\
\text { Improved road safety } \\
\text { where the design team } \\
\text { highlights any hazard } \\
\& \text { modify any error } \\
\text { during the design stage } \\
\text { - The cost integration } \\
\text { facilitated the adoption } \\
\text { of different target cost } \\
\text { techniques during } \\
\text { various project stages }\end{array}$ & $\begin{array}{l}\text { Knutt } \\
(2014)\end{array}$ \\
\hline $\begin{array}{l}\text { M25 Motorway } \\
\text { Upgrade of the M } 25 \text { orbital motorway in London for the Olympics } \\
\text { in } 2012 \text { used BIM to create 3D models of infrastructure to an } \\
\text { agreed level of detail. This information was required to enable the } \\
\text { project to be delivered on a faster timescale than would typically be } \\
\text { required for a scheme of this nature. With a number of stakeholders } \\
\text { in the delivery team, the information/models from each discipline } \\
\text { were integrated through Autodesk Navisworks which provided an } \\
\text { opportunity to undertake clash detection exercise. The final BIM } \\
\text { models were issued to the construction team for use on site with } \\
\text { three quarter of staff having access to these models for use on a } \\
\text { range of tasks including daily briefings and communicating design } \\
\text { information. Having gone from an initial desire to create a } \\
\text { buildable design that didn't have clashes, the result was a vast } \\
\text { amount of useful data that could be attributed to objects and cost } \\
\text { effectiveness. }\end{array}$ & $\begin{array}{l}\text { The project collates vast } \\
\text { amount of useable } \\
\text { information which can be } \\
\text { utilized in operation and } \\
\text { maintenance phase after } \\
\text { construction } \\
\text { Use of BIM in a project } \\
\text { lifecycle where teams have } \\
\text { come together and } \\
\text { collaborated successfully } \\
\text { - Cost reduction }\end{array}$ & $\begin{array}{l}\text { Burleigh } \\
\text { (2012) }\end{array}$ \\
\hline
\end{tabular}

In the A556 project, the project the team is enabling a digital handover model to an Integrated Asset Management System (IAMS), which will replace 17 agency and suppliers systems within one single integrated system for operations management. Systems like drainage data management system, structure management 
information system, and geotechnical data management system are all integrated within one Geographical Information System. The integrated system will hold information as asset attributes which define the characteristics of an individual asset. Moreover, IAMS endorses components to know what they are and where they are situated within the project. This offers massive benefits to the contractor when work starts on-site, as it allows employees to use 'iPads' to navigate to their position of work, inter- connecting with the master design. To enable IAMS, a digital handover was put in place. The process mainly utilised Construction Operations Building Information Exchange (COBIE) to allow different sources of information to be interoperable e.g. bridges and retaining were imported from Civil 3D to Revit, then families created and parameters identified.

| Files were then exported to IFC and to COBIE. The process starts by capturing information from site digitally using mobile technology, the captured information will be stored in the cloud platform, and the information then | will be transformed from different digital format into IFC and then COBIE. The information is subsequently used to create AIM (Asset Information Model) which is used as a single source to store all information related to this project. AIM allows a smooth and easy way to search for any needed information during the operational phase of the asset.

Use of BIM in a project lifecycle where multiple stakeholders collaborate and produce vast of data. However, use of BIM in a project lifecycle is not the only data source, other systems (e.g. GIS, ERP etc.), stakeholders (such as contractors, subcontractors, client, suppliers etc.), site data collection technologies (such as RFIDs, wireless sensors etc.) and external data (web streams, social media, open data etc.) collate vast amount of data which can be utilized in operation and maintenance phase after construction. All this data creation and usage point to the four dimensions of Big Data: volume, variety, velocity and veracity (IBM, 2014). Data is considered 'Big' when it exceeds the capacity of traditional database management systems, doesn't fit in the structures of database architectures and posing challenges such as scalability, unstructured or semi-structured data, accessibility, real time analytics and fault tolerance (Satyanarayana, 2015). Managing this Big Data is critical where the Big Data movement seeks to glean intelligence from data (McAfee and Brynjolfsson, 2012) and to uncover patterns to guide decision makers using predictive and prescriptive analytics (Camm et al., 2015). For example, predictive modeling can be used for distribution of the performance variables to provide future maintenance needs, or to predict a single value for each performance variable and provide the location as well as volume of future maintenance (Taggart and Moss, 2016). Therefore, there is a need that in addition to leveraging BIM data for accurate maintenance of Highway assets, inventory and conditions, new opportunities as enabled by Big Data are also explored.

\section{RESEARCHMETHODOLOGICAL $¥$ APPROACH}

The encompassing theme of this research is emerging field of Big Data Analytics and its applications within Highways context This study employed different methods to provide a multi-faceted view of the problem area, both at specific Highways Scheme level as well as to understand broader issues faced by the industry. A literature review was initially performed to systematically gather information to identify and understand the problem domain. This literature along with discussed case studies became a starting point to understand role of BIM processes and technologies as a unified information exchange mechanisms through the asset life cycle.

Data management applications in other industries were also reviewed. Interviews were held with owner and contractors involved in Highways maintenance to develop a better understanding of key challenges. In total 10 interviews were conducted in a semi-structured manner, each lasting approximately an hour. Interviews were done to understand challenges in BIM Implementation on transportation infrastructure projects. Also, two industry workshops were organized. Each workshop involved over 50 participants and focus of each workshop was to understand BIM implementation challenges within Highways development projects and the role BIM can play in bridging inefficiencies resulting from loss of information at handover phases. The overall understanding lead to drawing up of user needs, gathering system requirements and eventually a system architecture design. Industry workshops were supported by a series of semi-structured interviews with industry experts, to provide an overview of key challenges encountered. Findings were used to identify Highway Sector needs for big data analytics and subsequent presentation of aA system architecture-is presented developed to address identified needs, to based on-leverage ing-BIM for accurate maintenance of whole life cycle asset data, for accurate maintenance of Highway assets, inventory and conditions. Key objective is to account for accurate archival of assets that Highways agencies possess, their locations and performance levels. New opportunities as enabled by

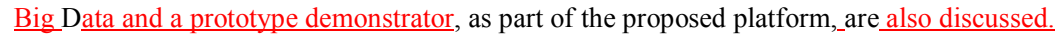




\section{SYSTEM ARCHITECTURE}

Traditionally the design and construction of an asset has been regarded as a separate and distinct phase from its operation and maintenance. There are significant information losses as major Highways and road development schemes are handed over from Design and Construction team to Operations and Maintenance. Lack of consistent data management across project life cycle may result in data generated in Design and Construction phase not being compatible with asset management software. As a result, information may require re-formatting and reentering. Also, gaps in information or incompatibility of data issues may only come to light at handover stage and result in delaying the handover. Also, more rigorous and time-consuming data checks may be required as asset managers have not had prior input and sign-off during the asset design and construction. All of this leads to poor management of data.

This section presents a system architecture and technology demonstrator based on having a single flow of information through the asset life cycle. As such, it enables end-to-end life cycle data management to enable Transportation agency and its suppliers to work alongside in a data driven environment from the scheme outset to its operations. A data driven approach enables a wide range of stakeholders to contribute to the development of the asset and the corresponding data is captured, developed and enriched in a consistent format. Interviews with Transportation agency and their supply chain highlighted that over past decade, there has been major investments in different types of reporting tools, IT and Enterprise Resource Management and back office systems. Very often accounting led software outputs are not well aligned with commercial and operational requirements of clients. Resulting fragmentation and inconsistent reporting has put enormous strains on operational and commercial teams. Resulting fragmentation affects key areas of business including reporting fragmentation, overlaps and duplication.

In developing the architecture (Fig 2), consideration has been given to the different types of data present in an asset's lifecycle - from the three dimensional physical data of the asset (augmented with it maintenance requirement) to the performance, cost and other data sets. These different types of data have been considered as layers which can be built up (one on top of another) to provide a multi-dimensional model and representation of the asset. Practically delivering this continuous and comprehensive flow of data requires a fully integrated approach in the deployment of technology.
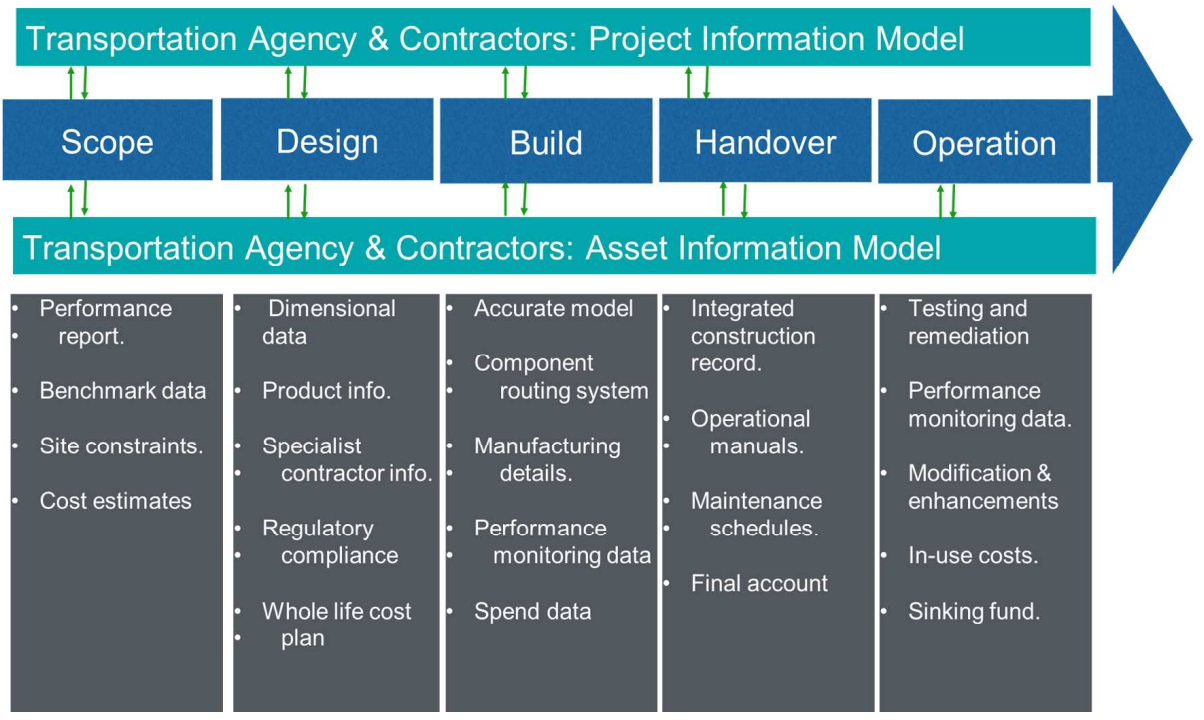

Figure 2: System Architecture 
The function of the technology platform is to be able to handle data at three levels: access; management and form. Firstly, at the access level, central concept is that of a BIM technology hub, which acts as a data repository for the asset concerned. In presented model, this is a physical server located at Transportation Authority with cloud based computational 3D models hosted on a central server. This allows a fast and secure local area network (LAN) access to be established for Transportation Authority and its suppliers, with remote access for site based operatives. Asset Information Model is used to define a standard format of data and using industry grade BIM software tools, data is generated and exchanged between multi-disciplinary teams. Common data environment (CDE) provides a platform to allow the exchange of this data into and out of the hub from stakeholders IT system. This CDE is enabled by languages and data protocols, such as Construction Operations Building Information Exchange (COBIE) - allowing the exchange of information. Open source IFD information (from catalogue or dictionary to detail asset component etc.) are used to allow data to be read by the platform and made available to its users. Using information exchange standards such as PAS1192:2 and PAS1192:3, such unified environment for data storage ensures stakeholders have confidence in the accuracy, completeness and relevance in the information being exchanged across various parties. Cloud based computing, including pooled computing resources and services delivered over the web, could provide an alternative to a central server located at Transportation Authority. This would have the added benefit of requiring lower (and thus cheaper) processing and ease of scalability if the system needs to be expanded. Concerns regarding the security and control of data using a cloud based platform, however, must be addressed. In addition to designing an appropriate architecture for the hardware and software platform, an additional layer of data management and control is needed to ensure the effective operation and integrity of the model (see Fig 3). This extends beyond the protocols for organizing data checking, verification and authorization. A key challenge faced by various Transportation agencies is that there critical data is often maintained externals by their service providers. Often data management involves various layers of bureaucracy within various IT departments. Consistent data flow supported by an Asset Information Model could help enhance collaboration between various stakeholders. This signifies a departure from the way traditional Electronic Data Management Systems (EDMS) operate. EDMS are file based - building up larger archives of detailed files on a related subject, with access to that data via the directory or search term and with limited cross referencing of the data. Using BIM and supporting standards, organizes information graphically, layering detailing (beyond the three dimensions of the physical data to include additional dimension of performance cost etc.) into 'meta data'. Data is simply retrieved, interrogated and updated by browsing and entering the graphical models rather than searching a library of files. This will enable better life cycle decisions. For instance, a civil engineer involve in road design will be able to analyse design models to quickly determine whether the road geometry meets safety parameters for sight distance. Data integration will allow them to consider not only the road layout, but also overlay this with other information which will impact on sight distance such as the road camber, visual obstructions (such as central barriers) and road-side foliage. Any gaps in the capability of the platform can be overcome by enhancing existing programmes by using plug-ins (e.g. which provide details of new specification) or by using software development kit (SDK) to create bespoke additional features and functionality. Users are able to interface with the platform using applications suitable for their work so project managers may use application such as Primavera within the platform rather than the $3 \mathrm{D}$ model orientated software that engineer would prefer. As such, the platform should be considered as a single integrated approach which provides the 'back office' for managing data and information and is flexible in allowing the user to interface with it based on their needs.

Improving the quality of information across all asset classes (i.e. structural, pavement, drainage, geo-technical works and technology) is a key to achieving operational efficiency and effectiveness. Augmenting asset data with performance, operational and maintenance data will help create a useful knowledge management strategy. This is enabled through continuous data capture related to the asset post construction, to provide an up-to-date and enriched data, captured from road-side sensors, hand held devices which record the activity of operational staff, drones which provide aerial surveys of the assets, and sensor data which monitors performance of the asset and enhancements / maintenance works carried out using the platform. It is acknowledged that some of the historical asset data will not be in a format that can be readily uploaded to the platform (see Fig 4). There are various tools (such as document imaging software) that are able to convert this information for uploading. When responding to either planned or responsive maintenance on drainage, the platform can be relied upon to generate data on the specific drainage system, the components used and its GIS location. This will allow operatives or contractors to arrive on site with the relevant knowledge and components to accurately excavate the relevant part of the drainage and make the repair. This work, in turn, can be captured by the platform using hand held on other 
mobile devices, ensuring information remains up-to-date.

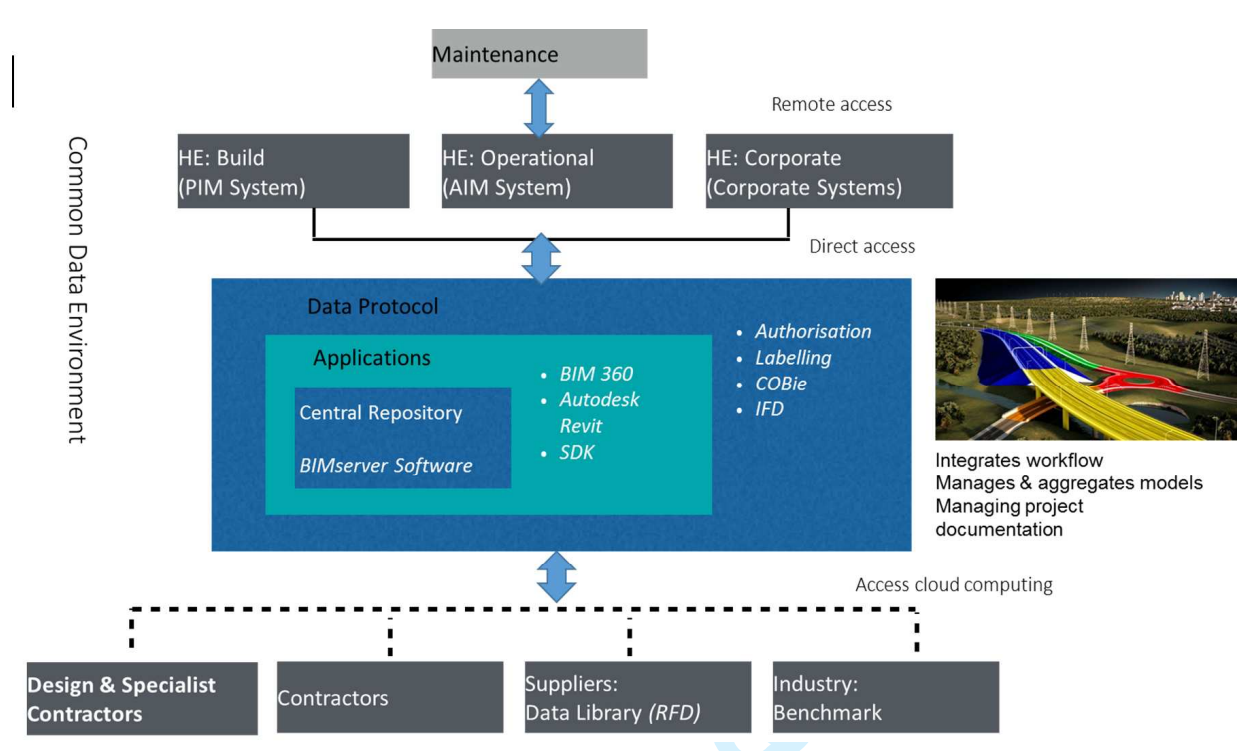

Figure 3: Integrated Data Environment
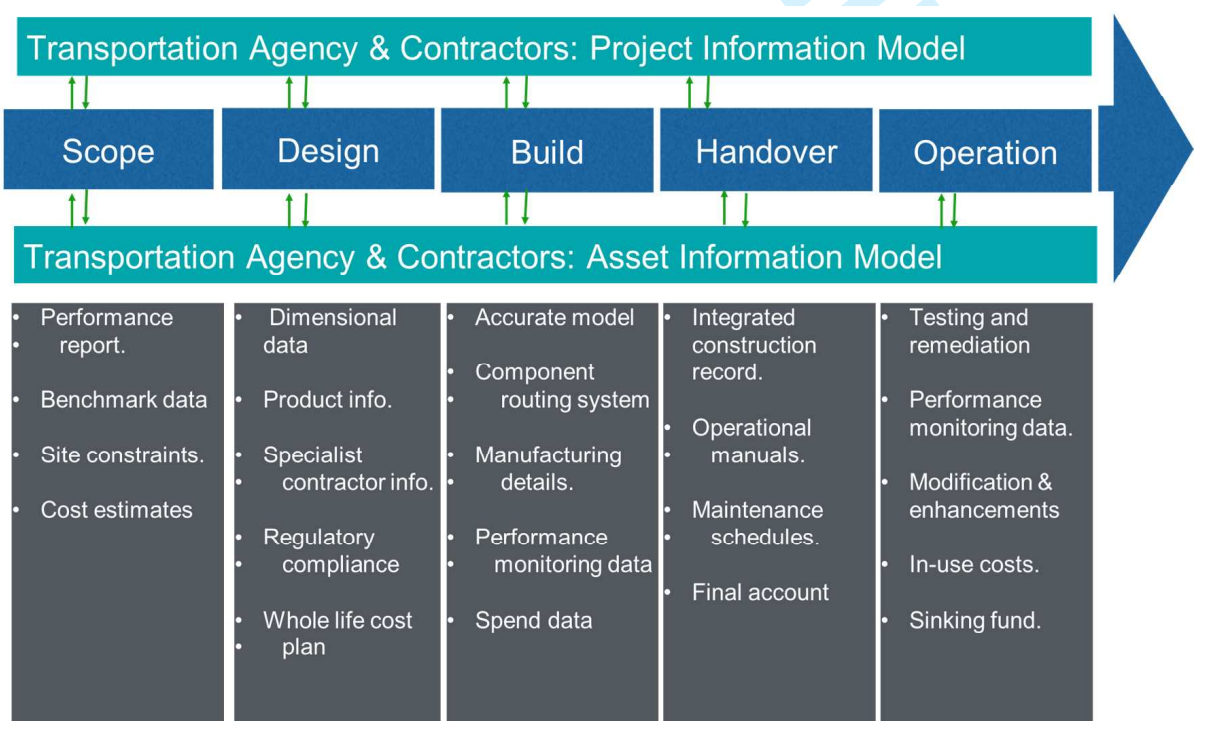

Figure 4: Data Management 
Effective asset management will allow for an asset that is fit for purpose and can be readily and cost effectively operated and maintained. This is achieved by defining standard asset information model, enabling early and continuous intervention by all of the relevant stakeholders and avoiding handover stage data losses. Having high quality, up-to-date data and information can be used to drive decision making and activity, particularly as this data is in a user-friendly visual format.

\section{INTEGRATION HIGHWAY MAINTENANCE AND OPERATIONS DATA WITH BIG DATA/ OPEN DATA OPPORTUNITIES}

Effective Road network management involves collection and analysis of vast amounts of data from a variety of sources including live traffic data, infrastructure data and operational and maintenance records. Recent growth in open data/big data analytics and data integration technologies provides new opportunities to optimise operations of Highways Infrastructure (e.g. use of cameras and sensors to monitor real time traffic flow, speed and travel times, GPS data to monitor journey times, data from telecom operators/social media apps to develop better understanding of journey patterns, asset data on condition of roads, etc). Opening up data (infrastructure related and network management) and linking it up with data from different sources provide new opportunities for optimisation. (e.g. road asset maintenance, cross-asset comparisons, provision of better information to road users, etc.).

Different data types are classified as below:

- Traffic Data Collected through Fixed sensors e.g. loop detectors which captures traffic data through wires embedded in the road or through cameras. It can measure congestion data.

- Traffic Data Collected through Mobile sensors: This include data collected through mobile phones via Bluetooth/telecom operators, satellite navigation, or onboard vehicle navigation systems. Could be used to capture key parameters such as time of travel, journey pattern, general speed on the road, and understanding of transportation key decisions.

- Road Asset Data: Accurate record of assets to optimise operations and maintenance. Big data offers new opportunities to investigate predictive analytics and analyse historical data. Recent applications include use of Ground Penetrating radars to maintain accurate records of road surface condition right to base layers, use of mobile ICT to capture on-site road condition data, use of crowdsourcing to obtain information about state of assets e.g. journey time captured through mobile apps.

- Open Data: UK government is producing significant amount of open data which is made available through open data portal (www.data.gov.uk). Datasets from this portal also offer opportunities for analysis and data visualization. Some examples of such datasets are: road safety data, road traffic counts, road casualties and accident data, road statistics (traffic, speeds and congestion), road conditions, road length statistics, out door air quality data, air pollutant and monthly/historical meteorological data for asset maintenance etc.

\section{5a. Hadoop Framework for Highway Road Asset and Traffic Management Data}

In UK, Smart Motorway Programme has been used to collect data from wide range of sensors (e.g. cameras, CCTV, traffic sensors) to monitor traffic data and adjust speed limit to optimise traffic flow (Inrix, 2012). With the rapid advancements in sensor technologies, in nowadays different types of RFID tags and wireless sensors are deployed in highways for asset management (Alavi et al., 2016). The problem is how to deal with the huge amount of data in an efficient way that has been collected from RFID readers, sensor gateways, mobile devices and open data repositories to transform it to meaningful information and to integrate it with BIM for effective visualizations that can be used by asset managers for management and monitoring of assets. The huge amount of data from multiple sources and their volume would be extremely enormous to the scale of the so called Big Data that can be analyzed by utilizing cloud computing technology (Zhou et al., 2016). The technology of cloud computing has merged to deal with the problem of big data storage and processing (Assunção et al., 2015). Among various open source cloud computing platforms, Hadoop is chosen to give to solution for BIM based assets management. Hadoop was created by Doug Cutting, the creator of Apache Lucene and best known for MapReduce and its distributed filesystem (HDFS) (Ghazi and Gangodkar, 2015). Hadoop has its origins in Apache Nutch, an open source web search engine, itself a part of the Lucene project (Ghazi and Gangodkar, 2015). System architecture based on BIM and Hadoop platform is illustrated in Fig 5. The real-time and historic data is collated from several systems and managed by a big data server (Hadoop cluster), which has high 
availability and fault tolerance capabilities and is equipped to handle a large volume and variety of data (Maitrey and Jha, 2015). External information system such as Geographical Information Systems (GIS) is integrated with the BIM server to provide the localization of real time assets of a highway. To take a benefit of the parallel processing that Hadoop provides, query for data extraction will be executed as a MapReduce job. Map Reduce is a distributed data processing model and execution environment that works by breaking the query processing into two phases: the map phase and the reduce phase (Jach et al., 2015). Whereas, HBase a Hadoop application, is a distributed column-oriented database built on top of HDFS and is used to query large datasets in real time (Qiu et al., 2011). HBase is not relational and does not support SQL, but it is able to do what an RDBMS cannot: host very large, sparsely populated tables created from different data sources on clusters made from commodity hardware (Lee et al., 2015).

\section{5b. Connectivity and data exchanges of BIM objects with Hadoop Cluster}

First of all, data from all sources that is logically mapped to BIM objects will be uploaded to HDFC via TCP connection. A TCP connection is established to the data server (Hadoop cluster) with the server's IP address and port number by executing a program written in Java. After a data file is successfully uploaded, the sensor application may move on to upload the next file and this process will keep on going until it reaches the upper limit of files. As soon as number of uploaded files reaches the defined upper limit, the TCP socket will be closed and MapReduce task will be triggered. To extract only the desired sensor data from data files, MapReduce will extract and then insert data to the HBase database system. The sensor data is inserted according to the column name it belongs to. A dynamic data connection is established between BIM server and Hadoop cluster. Proposed system GUI is invoked as a Revit Add In from Revit Structures GUI, using "External Tools" option. A selfupdating GUI is displayed with real-time sensor data. BIM plays a significant role in this process since the sensor data of the highways is populated with relevant parametric data from the BIM software. The asset manager can select the desired junction using its unique ID which will display its BIM model and information from the embedded sensors in that location. Establishing a data link that uniquely ties sensed data to a highway junction is all that is required to pair collected data to the space that it describes. Asset managers can connect to BIM server either by standard web browser or an Android Application that is developed to visualize the collected data from the data server. In addition, job scheduler application is also designed to automate the process of data acquisition.

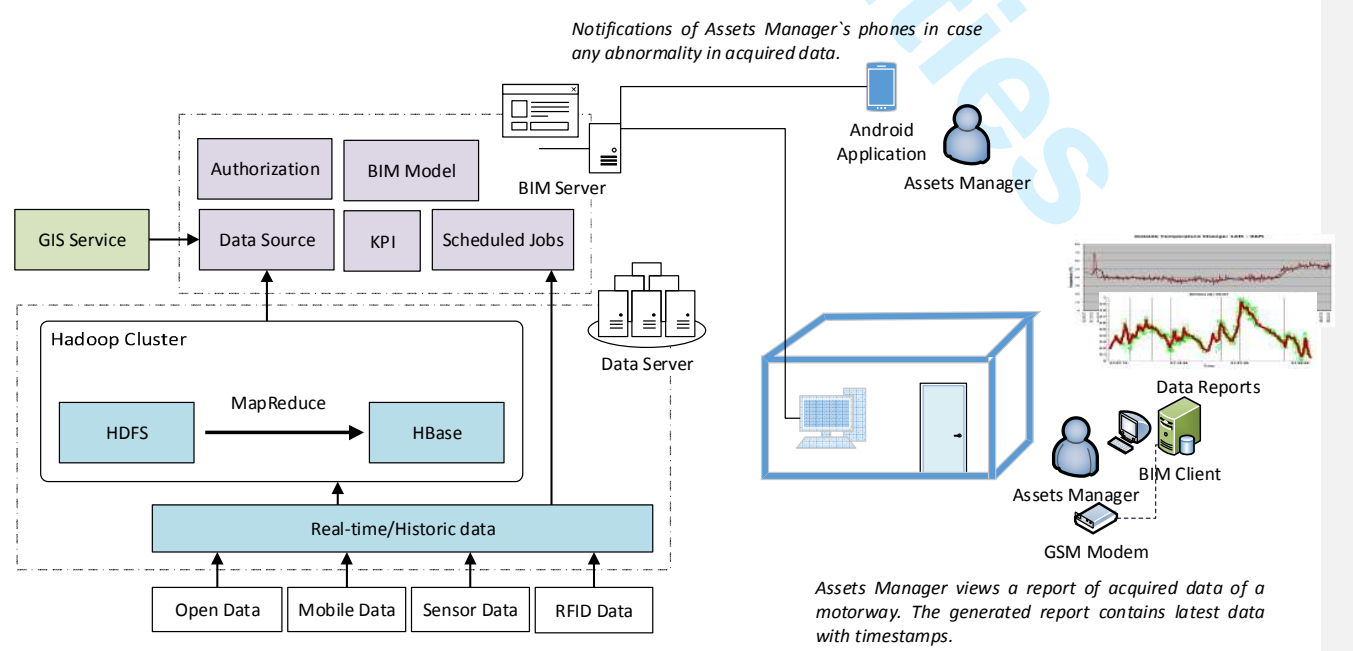

Figure 5: Hadoop and BIM Integration for Asset Management 


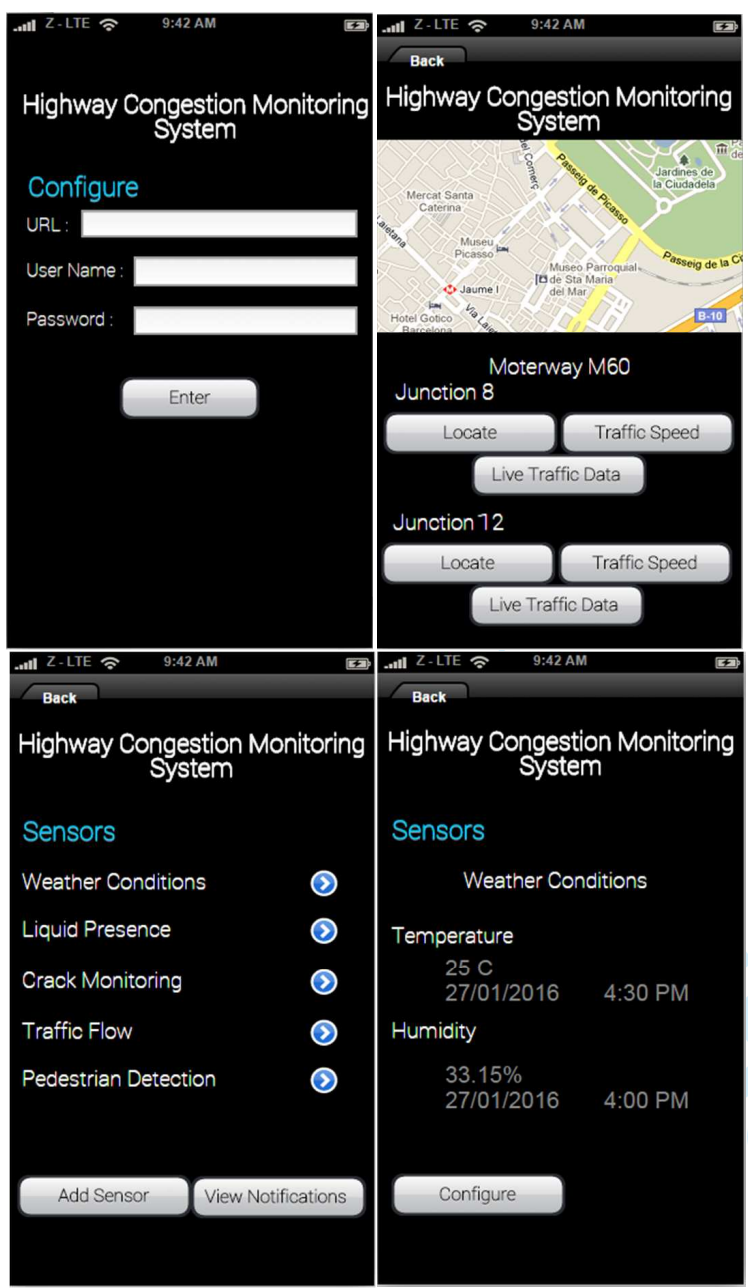

Figure 6: Highway Congestion Monitoring System Android Application

\section{5c. Prototype Mobile Application}

To keep updated with the acquired data, system should not only manage data acquisition from sensors but also synchronization and provide GUI to asset managers to remotely monitor data of a motorway and its assets. In order to do so, an Android based application is necessary. An Android based platform is chosen because of its free, open source and powerful software development kit (Janpla et al., 2015). Android prototype application, as part of the proposed platform, is designed using Eclipse and it is it is tested in Android Virtual Device (AVD). Eclipse is an integrated development environment (IDE) contains a base workspace and an extensible plug-in system for customizing the environment (Chopvitayakun, 2015). Written mostly in Java, Eclipse is used to develop applications. Wi-Fi (standard IEEE 802.11) is used for connectivity with a web database and access to database is protected with a username and password. Developed Android application has several functions which 
are: locating a motorway using "Google Maps", displaying live traffic data and traffic speed to avoid time sensitive emergency situations occurring on a motorway. The screen shots taken from AVD are shown in Fig 6.

\section{DISCUSSION AND CONCLUSIONS}

Building Information Modelling (BIM) supported by Big Data analytics has the potential to is revolutionizeing the way assets are conceived, designed, built and operated (Davis and Sharp, 2014). The success of BIM, however, depends on the effective integration of its three components: people, process and technology. This paper focused more on technology aspects related to life cycle data management. More specifically, it is | concerned with proposing a platform that integrates the various technologies and systems of Highways Authority and its supply chain, to allow for continuous flow of data throughout an asset's life-cycle, leading to seamless, collaborative and effecting working. The developed prototype application investigates the integration of BIM with Hadoop framework for Highway road asset and traffic data management. It aims to reduce whole-life costs of Highways through better real-time monitoring and to provide operatives or contractors with relevant knowledge.

Implementing a new technology platform to enable life cycle data management using BIM will have its challenges, but this will be outweighed by the significant benefits that can be realised with such an approach, particularly in relations to effectively delivering their programme of work whilst realising significant cost savings and multifaceted targets such as environmental, safety and road congestion reduction. Effective data management could provide transportation authorities data agility and could enable them to meet the everincreasing demands on the road network. With constant influx of data emanating from numerous sources, big data analytics provide a promising tool to support critical decision makingdecision-making within data rich environments. However, from expert opinion drawn from interviews within this research, it appears industry is $\underline{\text { slow to capitalise on emerging application scenarios and possibilities resulting from increasing volume, velocity }}$ and variety of data. Big data topic can mistakenly narrated as the remedy of unstructured data related problems within the industry or an emerging technology buzz word. Extracting true value from Big Data will require significant investments,investments supported by changed mindset and required skill sets. Existing contractual models and very fragmented structure of the industry could hinder data sharing and analytics among different parties. This requires industry and academia to work together to develop and drive a business case for BIM driven big data analytics for the indsutry.

As with any major change in the way of working, there will be several barriers and challenges to overcome in order to effectively implement the proposed platform. There are considerable costs involved in installing a new BIM based technology platform (relating to the outlay for the associated hardware, software and set up) and also the re-training of users to be able to effectively use that system. Use of Common Data Environment and COBIE standards could be seen as problematic by asset managers, who may see legacy systems being compromised through integration with larger BIM based technology platform. Standardising data and establishing new protocols for data management may require clear commitment from the workforce right from design and conception to asset management. Move towards integrated data management will involve major organizational cultural change. Resistance from various groups from within Transportation Agency or its supply chain may | provide a barrier towards more collaborative way of working. However, sSuch barriers are not insurmountable, and will require a forward looking leadership and clear vision. Introducing a data management approach which enables collaboration along with the other benefits, leading to cultural change in the mindset, supported by investments in technology infrastructure and skillsets, will act as a motivation to overcome resistance and sensitively handle re-organising working habits and protocols.

\section{REFERENCES}

Amir H. Alavi, Hassene Hasni, Nizar Lajnef, Karim Chatti, Fred Faridazar;(2016) An intelligent structural damage detection approach based on self-powered wireless sensor data, Automation in Construction, Volume 62, February 2016, Pages 24-44, ISSN 0926-5805.

BIM Task Group (2013a) Building Information Modelling (BIM) Task Group [ONLINE]. Available at: http://www.bimtaskgroup.org [Accessed 1 Dec 2015] 
BIM Task Group (2013b) PAS 1192:3 Specification for Information Management. [ONLINE]. Available at: http://www.bimtaskgroup.org/pas1192-3/ [Accessed 5 Nov 2015]

Burleigh, S. (2012) Using Building Information Modelling (BIM) to widen the M25. [ONLINE]. Available at: https:/www.ice.org.uk/disciplines-and-resources/case-studies/using-building-information-modelling-bimto-widen [Accessed 6 Nov 2015]

Camm J., Cochran J. and Fry M., Ohlmann W., Anderson D., Sweeney D., Williams T. (2015) "Essentials of Business Analytics", Cengage.

Chopvitayakun, S., Android Application to Enhance Performance of Internship Program Implementing Cloud Computing Platform and Infrastructure, Procedia - Social and Behavioral Sciences, Volume 197, 25 July 2015, Pages 2530-2538, ISSN 1877-0428.

Davis, A \& Sharp, D (2014). RICS Strategic Facilities Management - Case Study. London: RICS

UK Construction Strategy (2011) Government Construction Strategy, May 2011 [ONLINE]. Available at: https://www.gov.uk/government/uploads/system/uploads/attachment_data/file/61152/GovernmentConstruction-Strategy_0.pdf [Accessed 8 Oet 2015]

Ghazi, M.R. and Gangodkar, D. (2015) Hadoop, MapReduce and HDFS: A Developers Perspective, Procedia Computer Science, Volume 48, 2015, Pages 45-50, ISSN 1877-0509.

Government Soft Landings Policy (2012) The Government Soft Landings Policy - September 2012 [ONLINE]. Available at: http:/www.bimtaskgroup.org/wp-content/uploads/2013/02/The-Government-SoftLandings-Policy-18022013.pdf [Accessed 8 Oct 2015]

Highways England (2016) Operational Metrics Manual [ONLINE]. Available at: https://www.gov.uk/government/uploads/system/uploads/attachment_data/file/496470/Operational_Metri cs_Manual_January_2016.pdf[Accessed 29 Jan 2016]

IBM (2014) Extracting business value from the 4 V's of big data. [ONLINE] Available at: http://www.ibmbigdatahub.com/infographic/extracting-business-value-4-vs-big-data [Accessed: 23 Jan $2016]$

Inrix (2012). 'England's Highways Agency Selects INRIX Real-Time Traffic and Travel Time Information for its National Traffic Information Service'.

Jach, T., Magiera, E. and Froelich, W. (2015) Application of HADOOP to Store and Process Big Data Gathered from an Urban Water Distribution System, Procedia Engineering, Volume 119, Pages 1375-1380, ISSN 1877-7058.

Janpla, S., Bumrugrad, P., Kularbphettong, K. (2015) Developing a Traffic-Sign Knowledge Application on Android System, Procedia - Social and Behavioral Sciences, Volume 191, Pages 680-685, ISSN 1877 0428.

Knutt, E. (2014) COSTAIN SHOWCASES £174M EARLY BIM ADOPTER FOR HIGHWAYS AGENCY. [ONLINE]. Available at: http://www.bimplus.co.uk/projects/costain-showcases-174m-early-bim-adopterhighways-/ [Accessed 6 Nov 2015]

Lee, H., Shao, B. and Kang, U. (2015) Fast graph mining with HBase, Information Sciences, Volume 315, Pages 56-66, ISSN 0020-0255.

McAfee A. and Brynjolfsson E. (2012) Big Data: The management revolution. Harvard Business Review. October 2012. pp 59-68.

Maitrey, S. and Jha, C.K. (2015) MapReduce: Simplified Data Analysis of Big Data, Procedia Computer Science, Volume 57, Pages 563-571, ISSN 1877-0509.

Marcos D. Assunção, Rodrigo N. Calheiros, Silvia Bianchi, Marco A.S. Netto, Rajkumar Buyya, Big Data computing and clouds: Trends and future directions, Journal of Parallel and Distributed Computing, Volumes 79-80, May 2015, Pages 3-15, ISSN 0743-7315. 
Mordue, S. (2013) National Building Specification, PAS 1192:3. [ONLINE]. Available at: http://www.thenbs.com/topics/bim/articles/pas1192-3.asp [Accessed 14 Dec 2015]

Qiu, Z., Lin, Z. and Ma, Y. (2011) Research of Hadoop-based data flow management system, The Journal of China Universities of Posts and Telecommunications, Volume 18, Supplement 2, Pages 164-168, ISSN 1005-8885.

Rogers, D. (2014) Case Study Bradford College's David Hockney Building. [ONLINE]. Available at: http://www.bimplus.co.uk/projects/bradford-college/ [Accessed 6 Nov 2015]

Satyanarayana L. V. (2015) A Survey on Challenges and Advantages in Big Data. International Journal of Computer Science and Technology. Vol. 6, Issue 2, pp. 115-119

Steel, J., Drogemuller, R. and Toth, B. (2012). "Model interoperability in building information modelling", Software and Systems Modelling, Vol. 11 No. 1, pp. 99-109

Taggart, A. and Moss, B. (2015) Using asset management to deliver well-maintained highways. [ONLINE]. Available at: http:/www.atkinsglobal.com/ /media/Files/A/AtkinsGlobal/Attachments/sectors/roads/library-docs/technical-journal-1/using-asset-management-to-deliverwell-maintained-highways.pdf [Accessed 14 Dec 2015]

UK Construction Strategy (2011) Government Construction Strategy, May 2011 [ONLINE]. Available at: https://www.gov.uk/government/uploads/system/uploads/attachment data/file/61152/GovernmentConstruction-Strategy 0.pdf [Accessed 8 Oct 2015]

Zhou, K., Fu, C. and Yang, S. (2016) Big data driven smart energy management: From big data to big insights, Renewable and Sustainable Energy Reviews, Volume 56, Pages 215-225, ISSN 1364-0321. 


\title{
$\underline{\text { Response to Reviewer's Comments }}$
}

\begin{abstract}
Authors will like to thank reviewers for their comments and useful insights. We have revised the paper based on comments received. Following Table presents response to reviewer's comments.
\end{abstract}

\begin{tabular}{|c|c|}
\hline Reviewers Comments to Author & $\begin{array}{l}\text { Authors Response to Reviewer's } \\
\text { Comments }\end{array}$ \\
\hline $\begin{array}{l}\text { 1. While the introduction section sets } \\
\text { the scene for the paper, the word } \\
\text { proposing a platform seems more } \\
\text { appropriate than providing a } \\
\text { platform. The last paragraph of this } \\
\text { section is merely a content list of the } \\
\text { paper, showing how these sections } \\
\text { will add value to one another. For } \\
\text { example, if emerging standards are to } \\
\text { be discussed, how such discussion } \\
\text { will benefit the forthcoming steps. } \\
\text { Also, methodological approach } \\
\text { would be more appropriate to use, } \\
\text { than methodology. }\end{array}$ & $\begin{array}{l}\text { Many thanks for Reviewers } \\
\text { comment. This comment has now } \\
\text { been addressed in the revision with } \\
\text { suggestion on providing a platform } \\
\text { removed from the paper. Last } \\
\text { paragraph of Section } 1 \text { has been } \\
\text { rewritten to indicate connectivity } \\
\text { between various Sections. }\end{array}$ \\
\hline $\begin{array}{l}\text { 2. State of the art review. It is not } \\
\text { clear what added value table } 1 \text { brings } \\
\text { to the paper. Which elements of these } \\
\text { case studies actually feed into the } \\
\text { methodology section? What is the } \\
\text { underpinning theory that underpins } \\
\text { the methodology? It seems that the } \\
\text { methodology sets off by itself, } \\
\text { without relying on the findings from } \\
\text { literature. What is the methodology? } \\
\text { The workshops, interviews etc... what } \\
\text { were their objectives, how were they } \\
\text { planned, did they have a timeline? } \\
\text { What were the findings from these }\end{array}$ & $\begin{array}{l}\text { Table } 1 \text { presents two relevant case } \\
\text { studies linking conceptual } \\
\text { discussion with practical } \\
\text { application. Section } 3 \text { has been } \\
\text { rewritten to address various } \\
\text { comments raised by the reviewer. }\end{array}$ \\
\hline
\end{tabular}




\begin{tabular}{|c|c|}
\hline $\begin{array}{l}\text { workshops that fed into the proposed } \\
\text { platform? }\end{array}$ & \\
\hline $\begin{array}{l}\text { 3. The system architecture section } \\
\text { could have kicked off by itself, } \\
\text { without the previous parts of the } \\
\text { paper. There is not clear } \\
\text { methodological steps or rationale } \\
\text { behind the development of the system } \\
\text { architecture. }\end{array}$ & $\begin{array}{l}\text { Detailed discussion has been added } \\
\text { in Section } 4 \text { prior to presentation of } \\
\text { the system architecture. Also, } \\
\text { Section } 3 \text { discusses how } \\
\text { identification of user needs in earlier } \\
\text { phases of research laid basis for } \\
\text { development of system architecture. }\end{array}$ \\
\hline $\begin{array}{l}\text { 4. Please be consistent with the use of } \\
\text { terms. While in parts of the paper you } \\
\text { make reference to a platform, in other } \\
\text { parts you call is a prototype } \\
\text { application. }\end{array}$ & $\begin{array}{l}\text { This has been addressed in paper } \\
\text { revision. . Word prototype is used } \\
\text { where 'prototype' is presented and } \\
\text { use of "platform" has been } \\
\text { eliminated to avoid any confusion. }\end{array}$ \\
\hline $\begin{array}{l}\text { In general, I feel there is enough meat } \\
\text { in this paper. However, the paper } \\
\text { could be marginally improved by } \\
\text { displaying the pre-development } \\
\text { stages of the proposed system, then } \\
\text { the developmental stages, with a } \\
\text { description of the post developmental } \\
\text { stages. }\end{array}$ & $\begin{array}{l}\text { Paper presents a conceptual } \\
\text { discussion. Various stages of } \\
\text { development have been addressed } \\
\text { within Section } 3 \text { and } 4 \text {. }\end{array}$ \\
\hline $\begin{array}{l}\text { The literature review and the paper's } \\
\text { link to the past works are weak. The } \\
\text { referencing to empirical academic } \\
\text { works in the field is scarce, } \\
\text { particularly in the introduction and } \\
\text { state of the art review sections. The } \\
\text { paper fails to show the gap or the } \\
\text { base of its argument from the } \\
\text { literature. For instance, } \\
\text { - How did you identify the categories } \\
\text { for the data required for smooth } \\
\text { operation of Highways? } \\
\text { - Very little discussion based on the }\end{array}$ & $\begin{array}{l}\text { Thank you for identifying the gap. } \\
\text { Literature review has been updated. } \\
\text { A discussion on big data and } \\
\text { analytics has been added and the } \\
\text { reference list has also been updated. }\end{array}$ \\
\hline
\end{tabular}




\begin{tabular}{|c|c|}
\hline $\begin{array}{l}\text { main Big Data literature body. What i } \\
\text { actually s Big Data? What are the } \\
\text { concerns/challenges before it? What } \\
\text { types of analytics/ implementations } \\
\text { can potentially yield what benefits? } \\
\text { - Any past references that } \\
\text { show/discuss the benefits of using } \\
\text { life-cycle data in asset management } \\
\text { (buildings, highways etc) } \\
\text { - Beyond government task groups' } \\
\text { reports and BIM specs, the paper } \\
\text { seems to have overlooked the } \\
\text { accumulating literature on the use of } \\
\text { BIM in asset management and } \\
\text { handover (could also be for building } \\
\text { assets). } \\
\text { - No specific discussion on how } \\
\text { highways asset } \\
\text { maintenance/handover is different } \\
\text { from or similar to building asset } \\
\text { management/handover in terms of } \\
\text { data requirements and management, } \\
\text { in which comparatively more } \\
\text { academic works on the subject could } \\
\text { be found. }\end{array}$ & \\
\hline $\begin{array}{l}\text { - Please ensure that the in-text } \\
\text { references match with the references } \\
\text { in your references section. }\end{array}$ & $\begin{array}{l}\text { All references have been checked to } \\
\text { ensure alignment. }\end{array}$ \\
\hline $\begin{array}{l}\text { 3. Methodology: Is the paper's } \\
\text { argument built on an appropriate base } \\
\text { of theory, concepts, or other ideas? } \\
\text { Has the research or equivalent } \\
\text { intellectual work on which the paper } \\
\text { is based been well designed? Are the } \\
\text { methods employed appropriate?: The }\end{array}$ & $\begin{array}{l}\text { Section } 3 \text { has been revised to } \\
\text { address comments made by } \\
\text { reviewers. }\end{array}$ \\
\hline
\end{tabular}




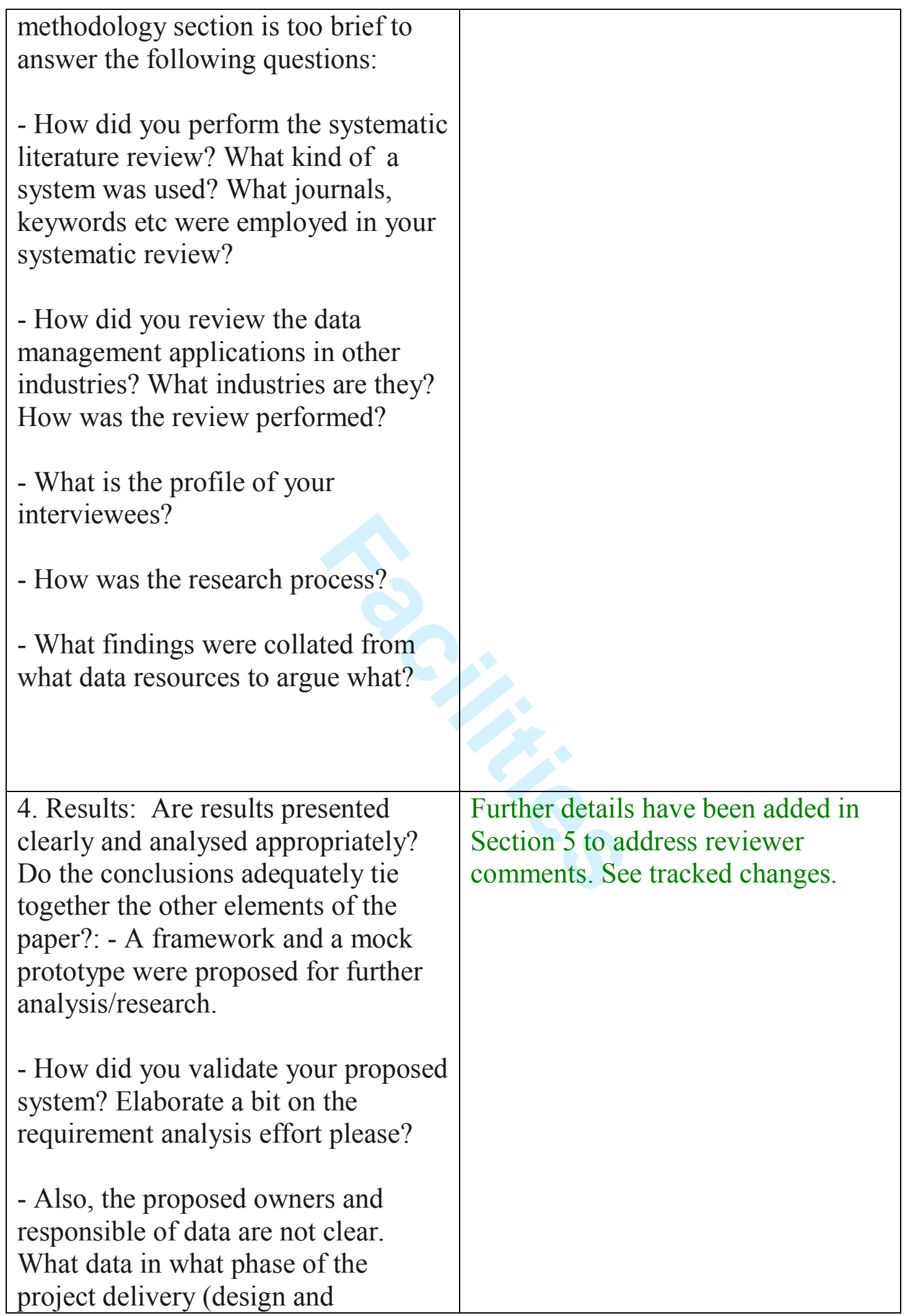


construction will be required)?

- The most important part of Big Data discussions is not clear however; what kind of data analytics is proposed in terms of analysis techniques and expected value? In other words, beyond the hardware and data collection means/ data resources (sensors, mobile devices etc), what will be the analytics part? What will be the expected hidden trends/findings from the analytics? Predictive maintenance? maintenance resource allocation? decision making framework creation? The value of the analytics is not clear.

- How the data handover will be managed?

-How about the return of investment (ROI); what could be the expected benefits and their monetary return?

- Many technical terminology and some buzzwords (BIM Level 3, Hadoop Server, Big Data etc); However, no proper discussion of the technical and managerial challenges before the application of the proposed prototype. Data privacy issues, contractual systems/ project delivery methods, trained people requirements etc etc ??

- What do you suggest for future actions/ research?

5. Implications for research, practice and/or society: Does the paper 
identify clearly any implications for research, practice and/or society? Does the paper bridge the gap between theory and practice? How can the research be used in practice (economic and commercial impact), in teaching, to influence public policy, in research (contributing to the body of knowledge)? What is the impact upon society (influencing public attitudes, affecting quality of life)? Are these implications consistent with the findings and conclusions of the paper?: With the constant influx of data from many different resources, Big Data analytics present a promising tool for decision making in data rich environments. Despite the ever increasing volume, velocity and variety of construction/asset management data, the industry has been slow in taking on the main stream Big Data discussion, which is in part fuelled by consultants and large vendors. Also, the topic can sometimes be treated superficially as some sort of a buzz word and mistakenly narrated as the remedy for data related problems in the industry. Extracting value from Big Data analytics requires significant investment with qualified workforce, and the business case is just not there for the industry still. Also, the structure of the industry can hinder data sharing and analytics among different parties.

This paper is interesting in the way
Many thanks for useful comments by reviewers. We have made changes within various Sections of the paper as outlined above to address changes suggested by reviewer. Also, Discussion and conclusions Section has been rewritten to address identified changes. 


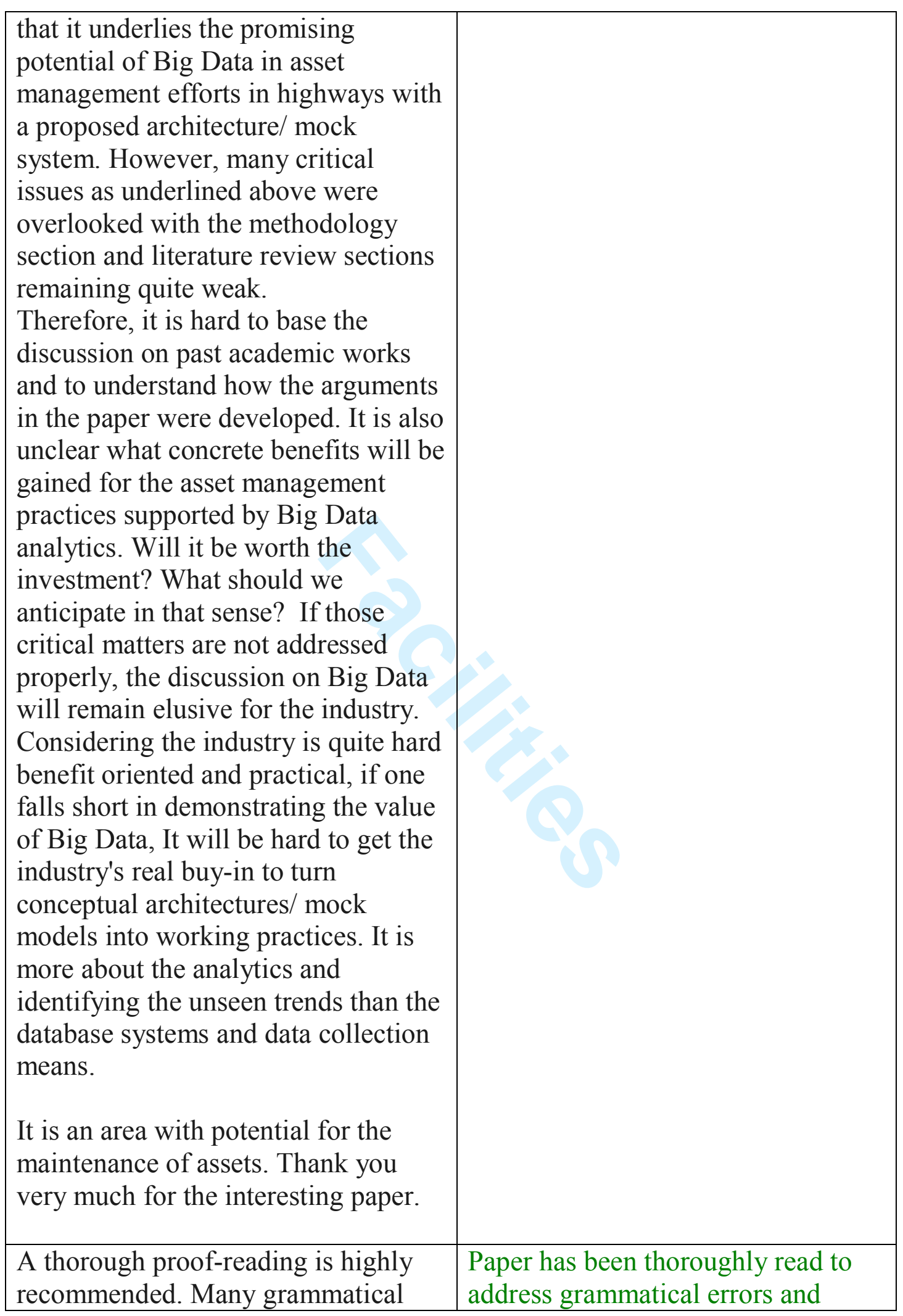


\begin{tabular}{|l|l}
\hline errors and typos were identified. & typos.
\end{tabular}

Those errors affect the

communication quality of the paper.

Please carefully read through the paper from start to finish and improve the language quality. Specific examples can be given from the paper if required. 